\begin{tabular}{|c|c|}
\hline \multirow{3}{*}{  } & $\begin{array}{l}\text { International Journal of Trend in Scientific } \\
\text { Research and Development (IJTSRD) }\end{array}$ \\
\hline & International Open Access Journal \\
\hline & ISSN No: 2456 - 6470 | www.ijtsrd.com | Volume - 2 | Issue - 4 \\
\hline
\end{tabular}

\title{
Reverse Aging by Punica granatum L. Peel Extract on Rat Model
}

\author{
Akanksha Samuel $^{1}$, Yogita Dobhal $^{2}$ \\ ${ }^{1}$ Assistant Prof, ${ }^{2}$ Assistant Prof \\ ${ }^{1}$ Smt. Vidhyavati Group of Institutes Goramachhiya, Jhansi, Uttar Pradesh, India \\ ${ }^{2}$ Sardar Bhagwan Singh Post Graduate Institute, Balawala, Dehradun, Uttrakhand, India
}

\section{ABSTRACT}

While connecting the dots to all the possibly known diseases, it lead us to a single root cause, an increased level of free-radicals. Apart from the external sources, internally sources as well, trigger the natural-agingclock i.e. the length of the telomere. The present study was focused on the chemical constituents being, polyphenolic tannins (ellagic acid, punicallin, punicalagin) being converted into urolithins. Ageing was induced by oral administration of soft-drink for 6 weeks in positive control group resulted increase in body weight, lipid-peroxidase \& low-density lipids. The oral administration dose of pomegranate aqueous peel extract in group T1(a) $50 \mathrm{mg} / \mathrm{kg}$ \& group T1(b) $10 \mathrm{mg} / \mathrm{kg}$ of body weight \& pomegranate fruit juice in group T2(a) $2 \mathrm{ml} / \mathrm{kg} \& \mathrm{~T} 2$ (b) $3 \mathrm{ml} / \mathrm{kg}$ of body weight, was given for 3 weeks.

Furthermore, the combination of both aqueous peel extract \& fruit juice in group T3 was $100 \mathrm{mg} / \mathrm{kg} \&$ $3 \mathrm{ml} / \mathrm{kg}$ of body weight administered orally. The pomegranate aqueous peel extract shown to be a potent antioxidant than the pomegranate fruit juice. Whereas, among all the treatment groups, group T3 shown significant increase in superoxidases, reduced glutathione, free radical scavenging activity, highdensity lipids \& memory retention as compared to the positive control group.

Keywords: free radicals, telomere, antioxidant, ORAC, Punica granatum L., ellagic acid, punicallin, punicallagin, polyphenol, polyphenolic tannins, urolithins, anti-aging.

\section{Introduction}

Aging cannot be composed in single a sentence. Hence, we sum it up as the process of becoming older physically, biologically,

psychologically \&

socially. ${ }^{[1,2,3]}$ Rudimentary changes in the human body are due to maturation (mentally, physically) \& changes in the level of hormones. These when juxtaposed with a younger body, clearly proves the action of ageing with significant results.

Based on assumptions from ancient times, the root cause of ageing was considered as the free radical increment in the body by external sources. In 1934, calorie restriction theory claimed to increase life span by 2 folds and cut back on cellular senescence. ${ }^{[4]}$ Until, Micheal Ristow coined the reactive oxygen species theory, also known as the free radical theory, which claims an internal source of the free radicals is what causes the hike. Thus, framing mitochondria for emitting reactive oxygen species in the body constantly ${ }^{[5]}$. This diverted the attention of audience towards an inbuilt program in endocrine as well as in nervous system. The factor triggering the natural process of ageing was dependent on the length of the cap of chromosome i.e. the telomere. The length of chromosome decreased (split) at every cell division but split more than the normal range when under the concentration of free radicals, making it non-existent, which changes apoptosis (natural cell death) to necrosis (unplanned cell death). Hence, the length of the telomere was phrased as the molecular clock or the natural ageing clock by Hay Flick. ${ }^{[6]}$

The following figure 1.1 elaborates the mechanism of necrosis by free radicals. 
Mechanisms of oxidative cellular damage

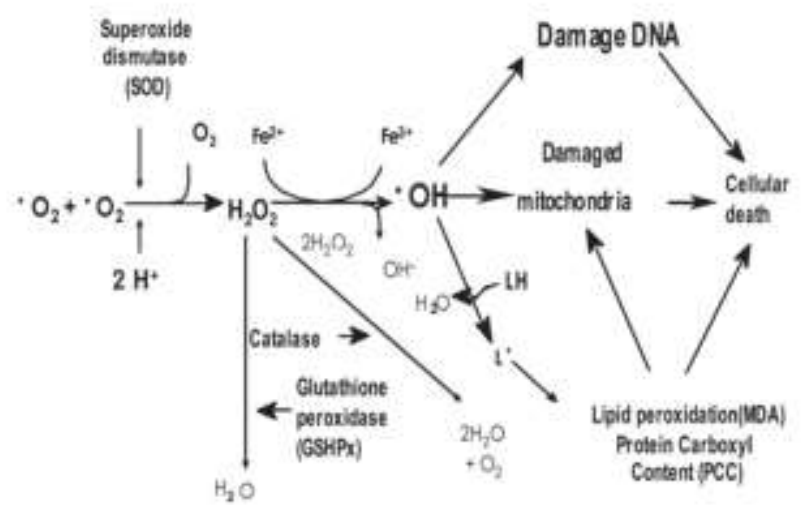

Figure 1.1- mechanism of oxidative cellular damage

Antioxidants play a major role in quenching the free radicals with ions and make them stable. Thus lowering the reactive oxygen species content in the body. According to the ORAC score (Oxygen radical absorption capacity) provided by the NIA (national institute of aging) at NIH (national institute of health), pomegranate tops the charts of high ORAC score in fruits/vegetables \& other food sources. ${ }^{[7]}$ Antioxidants plays vital role in inducing apoptosis in cancer cells, reduce skin ageing, heart disease, mood disorder, immune system, eye problems as well as memory loss issues. ${ }^{[8]}$ The objective of this study is to evaluate the reverse-aging property of Punica granatum L. peel extract. The study consists of inducing aging artificially by external sources such as carbonated soft drinks \& treating it with the help of antioxidant sources, juxtaposing with the naturally aged and younger models.

\section{Materials and Methods}

\section{Materials:}

Chemicals \& Reagents: DPPH, DTNB, HCL, Epinephrine bitartrate, Reduced glutathione, Thio barbituric acid, Trichloro acetic acid, Tris hydrochloride; Rankem. Ellagic acid; Sigma Aldrich. HDL kit, Urea kit; Erba. Pot.Hydrogen phosphate; Merck. Sodium bicarbonate, Sodium dihydrogen ortho phosphate; $\mathrm{CDH}$. Blood withdrawal capillary, Centrifuge tubes, Eppendorf, Micropipette tips; Himedia.

\section{Equipments:}

Analytical balance; Shimadzu. Hot air oven; Narang scientifics. Electric water bath; Remi motors. Centrifuge machine; Shimadzu. Spectrophotometer, Micropipette, Auto analyzer, Measuring cylinder,
Conical flask, Glass rod, Pipette, Volumetric flask, Beaker; Borosil.

\section{Methods:}

Preparation \& extraction of plant material: Punica granatum L., of Lythraceae family, was collected without authentification as its exclusive to India \& Iran. The extraction of fruit juice (PJ) was done by cold press method. The arils, or the small grains of the fruit was removed carefully, collected and crushed with manual pressure. No machines were used to extract the fruit juice. This fruit juice was stored in a sealed bottle below room temperature i.e. in the fridge. The stock was renewed weekly. The second extract was the fruit peel extract (PPE). The peels collected from the fruits used for first extract were dried at room temperature, as the sun light damages the polyphenolic content. The dried peels were then crushed in a mortar pestle and the remaining coarse particles were grind in an electric grinder. The fine powder obtained was then passed through sieves (no specific number) to remove the waste products that can't be used for further extraction process. The powder was weighed $20 \mathrm{gms}$ per $1 \mathrm{~L}$ water and $10 \mathrm{ml}$ ethanol (to prevent fermentation) for maceration process. The solution was placed in a conical flask with a magnetic bead, mouth covered with aluminum foil, over a magnetic stirrer. The solution is stirred for over 6 hours per batch at a constant speed of 500$1000 \mathrm{rpm}$. Per batch was filtered using a muslin cloth, and the liquid obtained was evaporated in a china dish, over a water bath for days, to obtain the desired consistency of the product. The final product was stored in a dark, vacuum sealed bottle to prevent hampering the antioxidant property. (Percentage yield was $19.77 \%$ )

\section{Animals:}

Wistar albino rats of body weight 150-250gm \& 6 months of age, of either sex were provided by the institutional animal house and the off springs (2 weeks old) were divided into similar age groups for the study. The animals were housed in standard polypropylene cages and maintained under controlled room temperature $\left(22 \pm 2^{\circ} \mathrm{C}\right)$ \& humidity $(55 \pm 5 \%)$ with 12:12 hour light and dark cycle. Every animal was provided with a commercially available rat pellet diet and water ad libitum. The guidelines of the CPCSEA (committee for the purpose of control and supervision of experimental animals) of Govt. of India were followed \& prior permission was granted from 
the Institutional Animal Ethics committee for conducting the animal experimental studies. Registration-no. IAEC/273/CPCSEA/SBS/003/20162017

\section{Experimental design/ protocol:}

Animals were divided into 5 main groups with 2 subgroups each of 2 specific groups. As per the protocol the dose was orally administered for 3 weeks disease induction \& 3 weeks disease treatment, while number of animals in each group was minimum 5. Group-I was the normal control group, which was administered saline orally. Then comes Group-II which is positive control group, administered only with soft drink, $1-2 \mathrm{ml}$ as their daily fluid needs. Now, Group-III is divided in two different doses i.e. T1(a) $50 \mathrm{mg} / \mathrm{kg} \& \mathrm{~T} 1$ (b) $100 \mathrm{mg} / \mathrm{kg}$ PPE by body weight. These groups were administered with soft drinks for first 3 weeks, to induce aging \& then administered with specific doses as per groups for another 3 weeks. In Group-IV the soft drink is is administered the first 3 weeks \& later PJ is administered, dividing the group in to two sub-groups i.e. T2(a) $2 \mathrm{ml} / \mathrm{kg} \& \mathrm{~T} 2$ (b) $3 \mathrm{ml} / \mathrm{kg}$. Then the last group, Group-V; T3 is a combination of T1(a) \& T2(a) doses. The group was administered with soft drink for the first 3 weeks like the other groups \& then treated with $2 \mathrm{ml} / \mathrm{kg}+50 \mathrm{mg} / \mathrm{kg}$ by body weight of the model.

\section{Table1.: QUALITATIVE PHYTOCHEMICAL SCREENING OF POMEGRANATE PEEL EXTRACT} (PPE) AND POMEGRANATE JUICE (PJ)

\begin{tabular}{|c|c|c|c|}
\hline \multirow{2}{*}{ Phytochemical tests } & Compound detected & \multicolumn{2}{|c|}{ Inference } \\
\cline { 2 - 4 } & & PPE & PJ \\
\hline Molish's test & Carbohydrates & ++ & +++ \\
\hline Benedict's test & Reducing sugar & ++ & +++ \\
\hline Keller Kiliani's test & Glycosides & + & ++ \\
\hline Xanthoproteic test & Protein & ++ & +++ \\
\hline Ninhydrin's test & Amino acid & ++ & +++ \\
\hline Ferric chloride test & Phenolic compound & +++ & ++ \\
\hline Ferric chloride test & Tannins & ++ & + \\
\hline Wagner's test & Alkaloids & + & + \\
\hline Lead acetate test & Flavanoids & ++ & +++ \\
\hline Froth's test & Saponins & + & ++ \\
\hline Salkowski's test & Sterols & + & + \\
\hline Saponification test & Fixed oils & - & + \\
\hline
\end{tabular}

,,,-++++++ refer to the intensity of the content 
The total phenolic content present in the fruit juice and peel had to compared as an estimate of the result expected. This is shown in the table 2., along with the free radical scavenging capacity/ total antioxidant capacity of each of them, using DPPH method.

Table 2.: TPC AND TAC ACTIVITY OF POMEGRANATE PEEL EXTRACT AND POMEGRANATE JUICE.

\begin{tabular}{|c|c|c|}
\hline Parameters & PPE & PJ \\
\hline $\begin{array}{c}\text { Total phenolic content (TPC); EA mg/g dry } \\
\text { weight }\end{array}$ & $58.63 \pm 0.129$ & $48.02 \pm 0.071$ \\
\hline $\begin{array}{c}\text { Total antioxidant capacity (TAC) by DPPH } \\
\left(\mathbf{E C}_{\mathbf{5 0}}, \boldsymbol{\mu g} / \mathbf{m l}\right)\end{array}$ & $20.296 \pm 0.05$ & $3.081 \pm 0.009$ \\
\hline
\end{tabular}

Mean values with \pm standard error, EA refers to Ellagic acid.

Biological \& physical parameters were systematically evaluated for the Punica granatum L. juice \& peel extracts with different dose levels, as mentioned earlier, used to treat the age induced rat models.

\section{Effect of Punica granatum L. on Body weight:}

In the present study soft drink (1-2ml/day) was administered orally in positive control group for 6 weeks to induce ageing. Positive control group shown weight gain \& compared to normal control group. Pomegranate aqueous peel extract $\&$ fresh juice were prepared. Treatment groups were divided on the basis of doses as, group T1 (a) peel extract $50 \mathrm{mg} / \mathrm{kg} \& \mathrm{~T} 1$ (b) peel extract $100 \mathrm{mg} / \mathrm{kg}$ of body weight. The group T2 (a) fruit juice $2 \mathrm{ml} / \mathrm{kg} \&$ group T2 (b) fruit juice $3 \mathrm{ml} / \mathrm{kg}$ of body weight. Group T3 peel extract + fruit juice $100 \mathrm{mg} / \mathrm{kg}+$ $3 \mathrm{ml} / \mathrm{kg}$ of body weight.

After 3 weeks treatment group T1 (b) results comparative weight loss. Whereas, among all the groups, group T3 results significant weight loss as compared to the positive control group, as mentioned in Table 3.

Table 3: Effect on body weight (gm)

\begin{tabular}{|c|c|c|c|c|}
\hline Groups & $\begin{array}{c}\text { Day } \\
0\end{array}$ & $\begin{array}{c}\text { Day } \\
7\end{array}$ & Day 14 & Day 21 \\
\hline Normal control & $180 \pm 7.071$ & $184 \pm 7.071$ & $187 \pm 7.071$ & $190 \pm 7.071$ \\
\hline Positive control & $180 \pm 17.67$ & $187 \pm 17.67$ & $190 \pm 14.00$ & $200 \pm 14.00$ \\
\hline T1(a) & $180 \pm 7.071$ & $176 \pm 7.071$ & $177 \pm 7.000$ & $175 \pm 7.000$ \\
\hline T1(b) & $185 \pm 7.483$ & $183 \pm 7.483$ & $180 \pm 7.736$ & $170 \pm 7.736$ \\
\hline T2(a) & $170 \pm 10.68$ & $171 \pm 10.68$ & $168 \pm 10.56$ & $165 \pm 10.56$ \\
\hline T2(b) & $180 \pm 6.782$ & $179 \pm 6.782$ & $176 \pm 7.026$ & $177 \pm 7.026$ \\
\hline T3 & $200 \pm 9.695$ & $197 \pm 9.695$ & $190 \pm 6.0 * *$ & $180 \pm 6.000 *$ \\
\hline
\end{tabular}

The statistical significance of difference between means is calculated by ANOVA followed by Dunett's test (post hoc test). Values were expressed as Mean \pm SEM ** $\mathrm{P}<0.001, * \mathrm{P}<0.01, \mathrm{n}=5$ in each group.

After 3 weeks treatment group T1 (b) results comparative increment in SOD level. Whereas, among all the groups, group T3 results significant increase in SOD level as compared to the positive control group (Table 4) 
Table 4: Effect on SOD levels (U/m L)

\begin{tabular}{|c|c|c|c|c|}
\hline Groups & Day 0 & Day 7 & Day 14 & Day 21 \\
\hline Normal control & $94.6 \pm 8.7$ & $85.1 \pm 16.3$ & $107.2 \pm 16.2$ & $98.2 \pm 10.3$ \\
\hline Positive control & $98.2 \pm 10.3$ & $103.1 \pm 9.3$ & $94.6 \pm 8.7$ & $85.1 \pm 16.3$ \\
\hline T1(a) & $85.1 \pm 16.3$ & $85.1 \pm 16.3$ & $98.2 \pm 10.3$ & $107.2 \pm 16.2$ \\
\hline T1(b) & $94.6 \pm 8.7$ & $110 \pm 10.8$ & $114.3 \pm 15.3$ & $114.3 \pm 15.3$ \\
\hline T2(a) & $98.2 \pm 10.3$ & $110 \pm 10.8$ & $107.2 \pm 16.2$ & $104.6 \pm 17.8$ \\
\hline T2(b) & $94.6 \pm 8.7$ & $107.2 \pm 16.2$ & $104.6 \pm 17.8$ & $110 \pm 10.8$ \\
\hline T3 & $91.1 \pm 18.05$ & $114.3 \pm 15.3$ & $114.2 \pm 13.9$ & $114.2 \pm 13.9$ \\
\hline
\end{tabular}

The statistical significance of difference between means is calculated by ANOVA followed by Dunett's test (post hoc test). Values were expressed as Mean \pm SEM ** $\mathrm{P}<0.001, * \mathrm{P}<0.01, \mathrm{n}=5$ in each group.

After the 3 weeks treatment of group T1 (b) results comparative increment in GSH level. Whereas, among all the groups, group T3 results significant increase in GSH level as compared to the positive control group (Table 6.3 \& figure 6.3 )

Table 5: Effect on GSH level ( $\mu \mathrm{mol} / \mathrm{m} \mathrm{L})$

\begin{tabular}{|l|l|l|l|l|}
\hline Groups & Day 0 & Day7 & Day 14 & Day 21 \\
\hline Normal control & $70.3 \pm 5.4$ & $70.3 \pm 5.4$ & $72.6 \pm 5.3$ & $70.3 \pm 5.4$ \\
\hline Positive control & $72.6 \pm 5.3$ & $70.3 \pm 5.4$ & $72.6 \pm 5.3$ & $70.3 \pm 5.4$ \\
\hline T1(a) & $78.6 \pm 7.7$ & $90.4 \pm 14.4$ & $90.4 \pm 14.4$ & $98.4 \pm 14.9$ \\
\hline T1(b) & $52.1 \pm 6.3$ & $66.6 \pm 4.9$ & $90.4 \pm 14.4$ & $106.2 \pm 20.4$ \\
\hline T2(a) & $66.6 \pm 4.9$ & $72.6 \pm 5.3$ & $75.4 \pm 18.3$ & $75.4 \pm 18.3$ \\
\hline T2(b) & $70.3 \pm 5.4$ & $72.6 \pm 5.3$ & $78.6 \pm 7.7$ & $90.4 \pm 14.4$ \\
\hline T3 & $75.4 \pm 18.3$ & $98.4 \pm 14.9$ & $106.2 \pm 20.4$ & $174.7 \pm 16.4$ \\
\hline
\end{tabular}

The statistical significance of difference between means is calculated by ANOVA followed by Dunett's test (post hoc test). Values were expressed as Mean \pm SEM ** $\mathrm{P}<0.001, * \mathrm{P}<0.01, \mathrm{n}=5$ in each group.

After the 3 weeks treatment, group T1 (b) results comparative increment in FRS level. Whereas, among all the groups, group T3 results significant increase in FRS level as compared to the positive control group (Table 6)

Table 6: Effect on antioxidant level FRS (m mol/L)

\begin{tabular}{|c|c|c|c|c|}
\hline Groups & $\begin{array}{c}\text { Day } \\
0\end{array}$ & $\begin{array}{c}\text { Day } \\
7\end{array}$ & Day 14 & Day 21 \\
\hline Normal control & $874.1 \pm 128.3$ & $667 \pm 128.3$ & $400 \pm 128.3$ & $366.3 \pm 53.6$ \\
\hline Positive control & $366.3 \pm 53.6$ & $366.3 \pm 53.6$ & $300 \pm 53.6$ & $300 \pm 53.6$ \\
\hline T1(a) & $874.1 \pm 128.3$ & $961.72 \pm 172.3$ & $\begin{array}{c}961.72 \\
\pm 172.3\end{array}$ & $987.2 \pm 218.3$ \\
& & & $1016 \pm 138.5$ & $1064.0 \pm 70.7$ \\
\hline T1(b) & $961.72 \pm 172.3$ & $987.2 \pm 218.3$ & $10.1 \pm 169.9$ & $816.1 \pm 169.9$ \\
\hline T2(a) & $366.3 \pm 53.6$ & $400 \pm 53.6$ & 810.9 & $895.6 \pm 314.8$ \\
\hline T2(b) & $816.1 \pm 169.9$ & $874.1 \pm 128.3$ & $869.6 \pm 125.5$ & 89.3 \\
\hline T3 & $895.6 \pm 314.8$ & $874.1 \pm 128.3$ & $1016 \pm 138.5$ & $1124.0 \pm 105.3$ \\
\hline
\end{tabular}

The statistical significance of difference between means is calculated by ANOVA followed by Dunett's test (post hoc test). Values were expressed as Mean \pm SEM ** $\mathrm{P}<0.001, * \mathrm{P}<0.01, \mathrm{n}=5$ in each group. 
International Journal of Trend in Scientific Research and Development (IJTSRD) ISSN: 2456-6470

After 3 weeks treatment group T1 (b) results comparative decrement in LPO level. Whereas among all the groups, group T3 results significant decrease in LPO level as compared to the positive control group (Table 7)

Table 7: Effect on LPO

\begin{tabular}{|l|l|l|l|l|}
\hline Groups & Day 0 & Day 7 & Day 14 & Day 21 \\
\hline $\begin{array}{l}\text { Normal } \\
\text { control }\end{array}$ & $46.85 \pm 0.16^{* * *}$ & $49.92 \pm 1.07$ & $49.92 \pm 1.07$ & $49.92 \pm 1.07$ \\
\hline $\begin{array}{l}\text { Positive } \\
\text { control }\end{array}$ & $51.7 \pm 1.08 * * *$ & $58.04 \pm 2.80 * * *$ & $61.22 \pm 3.11$ & $80.49 \pm 2.01$ \\
\hline T1(a) & $58.04 \pm 2.80 * * *$ & $50.40 \pm 0.75 * *$ & $50.40 \pm 0.75 * *$ & $46.85 \pm 0.16 * * *$ \\
\hline T1(b) & $58.04 \pm 2.80 * * *$ & $49.92 \pm 1.07$ & $46.85 \pm 0.16^{* * *}$ & $51.7 \pm 1.08^{* * *}$ \\
\hline T2(a) & $61.22 \pm 3.11$ & $58.04 \pm 2.80 * * *$ & $50.40 \pm 0.75^{* *}$ & $61.22 \pm 3.11$ \\
\hline T2(b) & $61.22 \pm 3.11$ & $49.92 \pm 1.07$ & $58.04 \pm 2.80^{* * *}$ & $58.04 \pm 2.80 * * *$ \\
\hline T3 & $51.7 \pm 1.08 * * *$ & $50.40 \pm 0.75 * *$ & $50.40 \pm 0.75^{* *}$ & $46.85 \pm 0.16^{* * *}$ \\
\hline
\end{tabular}

The statistical significance of difference between means is calculated by ANOVA followed by Dunett's test (post hoc test). Values are expressed in mean $\pm \mathrm{SEM} * * * \mathrm{P}<0.0001,{ }^{*} \mathrm{P}<0.001,{ }^{*} \mathrm{P}<0.01, \mathrm{n}=5$ in each group.

After 3 weeks treatment group T1 (b) results comparative increment in HDL \& decrement in LDL level. Whereas, among all the groups, group T3 results significant increase in HDL/decrease in LDL level as compared to the positive control group (Table $8 \& 9$ )

Table 8 \& 9 : Effect on lipid profile levels (mg/dl)

\begin{tabular}{|l|l|l|l|l|}
\hline Groups (HDL) & Day 0 & Day 7 & Day 14 & Day 21 \\
\hline Normal control & $1.00 \pm 0.26$ & $0.98 \pm 3.11$ & $0.97 \pm 3.11$ & $0.95 \pm 0.28$ \\
\hline Positive control & $1.10 \pm 0.16$ & $0.95 \pm 0.26$ & $0.90 \pm 0.09$ & $0.80 \pm 0.26$ \\
\hline T1(a) & $1.15 \pm 0.09$ & $1.25 \pm 0.09$ & $1.40 \pm 0.26$ & $1.42 \pm 0.42$ \\
\hline T1(b) & $1.40 \pm 0.16$ & $1.97 \pm 0.16$ & $4.68 \pm 0.09$ & $5.67 \pm 0.16$ \\
\hline T2(a) & $1.00 \pm 0.09$ & $1.08 \pm 0.09$ & $1.17 \pm 0.16$ & $1.21 \pm 0.09$ \\
\hline T2(b) & $1.80 \pm 0.16$ & $2.79 \pm 0.16$ & $3.78 \pm 0.09$ & $5.67 \pm 0.16$ \\
\hline T3 & $1.00 \pm 0.09$ & $2.09 \pm 0.09$ & $5.15 \pm 0.09$ & $6.21 \pm 0.09$ \\
\hline
\end{tabular}

\begin{tabular}{|l|l|l|l|l|}
\hline Groups (LDL) & Day 0 & Day 7 & Day 14 & Day 21 \\
\hline Normal control & $1.10 \pm 3.11$ & $2.24 \pm 0.09$ & $4.88 \pm 3.11$ & $5.20 \pm 0.16$ \\
\hline Positive control & $1.10 \pm 0.16$ & $1.90 \pm 0.28$ & $5.00 \pm 3.11$ & $5.53 \pm 3.11$ \\
\hline T1(a) & $1.10 \pm 3.11$ & $0.94 \pm 0.16$ & $0.72 \pm 0.09$ & $0.70 \pm 0.28$ \\
\hline T1(b) & $1.20 \pm 0.09$ & $1.15 \pm 0.28$ & $1.14 \pm 0.16$ & $1.12 \pm 3.11$ \\
\hline T2(a) & $1.05 \pm 3.11$ & $0.92 \pm 3.11$ & $0.88 \pm 0.09$ & $0.64 \pm 0.28$ \\
\hline T2(b) & $1.01 \pm 0.28$ & $0.94 \pm 0.16$ & $0.73 \pm 3.11$ & $0.57 \pm 0.09$ \\
\hline T3 & $1.15 \pm 0.09$ & $0.88 \pm 3.11$ & $0.67 \pm 0.16$ & $0.50 \pm 3.11$ \\
\hline
\end{tabular}

The statistical significance of difference between means is calculated by ANOVA followed by Dunett's test (post hoc test). Values were expressed as Mean $\pm \mathrm{SEM} * * \mathrm{P}<0.001,{ }^{*} \mathrm{P}<0.01, \mathrm{n}=5$ in each group.

Group T1 (b) results comparative increment in memory retention level. Whereas, group T3 results significant increase (Table 10) 
International Journal of Trend in Scientific Research and Development (IJTSRD) ISSN: 2456-6470

Table 10: Effect on memory retention by Morris Water Maze (sec)

\begin{tabular}{|c|c|c|c|c|}
\hline Groups & Day 0 & Day 7 & Day 14 & Day 21 \\
\hline Normal control & & & 120 & 120 \\
\hline Positive control & - & - & & \\
\hline T1(a) & 110 & 110 & 100 & 100 \\
\hline T1(b) & - & 100 & 90 & 95 \\
\hline T2(a) & 90 & - & - & 110 \\
\hline T2(b) & - & 110 & 95 & - \\
\hline T3 & 100 & 100 & 80 & 80 \\
\hline
\end{tabular}

The values are mean of the set of 3 readings per group per day.

\section{Discussion:}

Sodas/ soft-drinks are modern day's cigarettes \& cell's string like chromosomes are capped at either ends with a telomere, which are specifically targeted by the free radicals in the body. These telomeres work to keep the nucleic acid barred, hence working like the shoe lace tips. Every time a cell divides, the telomere splits on and on until they reach a stage when they can't anymore. At this stage the sells start to dysfunction, like a candlewick and burns down and cease to exist all at once.

In the present study, carbonated drink was administered (1-2ml/day/rat model), as the daily intake of liquid in rats is $1-2 \mathrm{ml}$ irrespective of the weight. The dependency on over consumption on softdrinks/ carbonated-drinks was maintained for 3 weeks orally to all the groups except the vehicle control group. The +control group was administered with soft drink alone \& no treatment at all. It showed increase in LPO \& LDL levels. Whereas, samples T1(a) peel extract $50 \mathrm{mg} / \mathrm{kg}$, T1(b) peel extract $100 \mathrm{mg} / \mathrm{kg}$, T2(a) fruit juice $2 \mathrm{ml} / \mathrm{kg}$, T2(b) fruit juice $3 \mathrm{ml} / \mathrm{kg} \& \mathrm{~T} 3$ peel extract + fruit juice $100 \mathrm{mg} / \mathrm{kg}+3 \mathrm{ml} / \mathrm{kg}$ respectively, showed signs of control \& even increment in physical \& memory retention levels, GSH, SOD, HDL, FRS levels at higher dose levels. T1(b) group gives a safe \& significant increment levels where as the group T3 gives us maximum levels if compared to the positive control group \& vehicle control group.

\section{Conclusion:}

In the present study, the combination of both juice $\&$ peel proved to be a great antioxidant source. Therefore, it could be concluded that pomegranate aqueous peel extract contains the essential constituents scavenging free-radicals, which is a natural ageing factor. On the beneficiary the peel extract is a greater source of antioxidant than the fruit itself and can play a major role in taking over the industry of anti-ageing products in future. Punica gramatum L. peel extract holds the key to a whole new world of cures for ailments, yet to be discovered.

\section{Acknowledgement:}

A sincere thanks to the concerned teachers, laboratory staff \& friends of the Department of Pharmaceutical Sciences, Sardar Bhagwan Singh Post Graduate Institute, Balawala, for the intellectual, technical \& emotional assistance throughout the term.

\section{Conflict of Interest:}

There are more than enough parameters to measure aging but the ones performed were most suitable. The only parameter that couldn't be performed due to technical unavailability was a comparison of telomere length before and after treatment. This specific parameter can conclude the claims made by the research study. 


\section{References:}

1) Norman.H, Zahnle, Kevin.j, Kasting, James.F, et al. 1989, "Annihilation of ecosystems by large asteroid impacts on early Earth". Nature London, Nature Publishing Group. V342 I(6246), pp 139142.

2) Maher, Kevin.A, Stevenson, David.J, 1988. "Impact frustration of the origin of life". Nature London V331 I(6157), pp 612-614.

3) Boysen.S.T,1996. Quantity-based interference,symbolic representations in chimpanzees (Pan Troglodytes. J Experimental Psychological Animal Behavior Process. ; V22, pp 76-86.

4) Gavrilov, L.A.Gavrilova, N.S. 2006. "Reliability Theory of Aging and Longevity", in Handbook of the Biology of Aging, Academic Press, San Diego, $C A$. pp. 3-42.Peter.M. Lansdorp Lessons from Mice without Telomerase 1997; V139 I(2) ,pp: 309-312.

5) Watts, Geoff , 2011. "Leonard Hayflick and the limits of ageing". The Lancet. V3 I7 pp: 2075.Graham.S.A., Hall.J., Sytsma.K., Shi.S. 2005. "Phylogenetic analysis of the Lythraceae based on four gene regions and morphology". Int. J. Pl. Sci. V166 I(6) ,pp: 995-1017
6) Ou.B, Hampsch-Woodill.M, Prior.R.L 2001. "Development and validation of an improved oxygen radical absorbance capacity assay using fluorescent as the fluorescent probe". J. Agric. Food Chem. V49 I(10), pp: 4619-26.

7) Kevin H. cheeseman, Margaret collins, Karen proudfoot, Trevor F. slater, T Graham W. burton,t Ann C. webbt and Keith U. ingoldt ,'Studies on lipid peroxidation in normal and tumour tissues The Novikoff rat liver tumour" Biochem. J. 1986 (Printed in Great Britain) Department of Biochemistry, Faculty of Science, Brunel University, Uxbridge V23 I5, pp 507-514.

8) Nat Protoc. "Measurement of superoxide dismutase, catalase, and glutathione peroxidase in cultured cells and tissue" Author manuscript, available in PMC 2011 Jan 1.Published in final edited form as Nat Protoc. 2010. Published online 2009, V5 I(1), pp: 51-66.

9) Clan Chem. Author manuscript "Direct Methods for Measuring HDL and LDL Cholesterol Compared with Ultracentrifugation" available in PMC 2015. Published in final edited form as, Clan Chem. 2010 June. Published online 2010 V56 I(6), pp: 977-986

10) Oberly Lw, Spitz DR. nitroblue tetrazolium, In: greenwald RA editor. Handbook of methods for oxygen radical. Research CRC press; Boca Raton, Florida; 1985. pp:217-220. 